\title{
BIBLIOGRAFÍA COMENTADA DE SALVADOR FERNÁNDEZ RAMÍREZ (1896-1983)
}

\section{Bienvenido Palomo Olmos}

Universidad Autónoma de Madrid

\section{INTRODUCCIÓN}

Salvador Fernández Ramírez nació en Madrid el 18 de mayo de 1896. Tras obtener la Licenciatura en Derecho y en Filosofía y Letras, se doctoró en Filología Española en 1948. Pero antes había completado su formación filológica en el Centro de Estudios Históricos, del que fue secretario entre 1932-1936, en la sección de Estudios Clásicos dirigida por el lingüista italiano Giulano Bonfante y en las secciones de Lengua y Literatura Españolas a la sombra de Ramón Menéndez Pidal, Américo Castro y Tomás Navarro Tomás, y había llevado a cabo una larga y eficaz actividad docente como profesor de Latín, Griego - catedrático de esta asignatura desde 1940 - Lengua y Literatura Española en Institutos de Bachillerato y Lengua y Literatura Española y Gramática Histórica en la Universidad Complutense de Madrid. Únase a su actividad docente su trabajo en el Consejo Superior de 
Investigaciones Científicas, como colaborador de la sección de Linguiística "Antonio de Nebrija» (1942-44), y en el Seminario de Lexicografía de la Real Academia Española desde 1948. Aquí, junto con Rafael Lapesa y Samuel Gili Gaya, adiestró en la técnica lexicográfica a becarios y colaboradores, dispuso la papeletización de obras fundamentales que no se habían tenido en cuenta, enriqueció el acervo del léxico hispano-americano y preparó una muestra del futuro Diccionario Histórico de la Lengua Española. El máximo honor de su carrera profesional fue el haber sido elegido académico de número de la Real Academia Española (3-12-1959), en la candidatura presentada por los señores Pemán, Gómez Moreno y Lapesa, para ocupar el sillón $Z$. Leyó su discurso de ingreso «Lengua literaria y norma lingüística» el 29 de mayo de 1960.

Rafael Lapesa (Boletín de la Real Academia Española, LXIII/1983, 15-28) y Manuel Seco (Revista de Filología Románica, I/1983, 297 302) han descrito con precisión la personalidad intelectual y humana de Fernández Ramírez en sendas notas necrológicas. Ellos destacan entre sus cualidades su capacidad de trabajo, su formación humanística, acrecentada por medio del contacto asiduo con la lengua y la cultura grecolatinas, sus preocupaciones pedagógicas y su conocimiento de la linguiística moderna, presente en todas sus descripciones de la gramática del español.

Manuel Seco lamentaba en su artículo de 1983 el hecho de que la obra científica de Salvador Fernández Ramírez solo pudiera encontrarse en las bibliotecas; $y$ animaba a la urgente recuperación editorial tanto de lo editado como de lo inédito. Así se demostraría que la figura de Fernández Ramírez es «una de las más destacadas en la linguiística española del siglo XX» (ibídem, pág. 298). La bibliografía que acabo de publicar en el Boletín de la Real Academia Española (1997) ilustra cuánto se ha avanzado en ese camino de recuperación editorial, que se inició gracias al generoso esfuerzo de don José Polo, profesor de la Universidad Autónoma de Madrid, y cuánto queda por recorrer.

En esta bibliografía comentada, de carácter más descriptivo que crítico, pretendo dar a conocer los contenidos fundamentales que nuestro gramático expuso en sus obras más importantes, tanto las que aún solo se pueden encontrar en bibliotecas como las que ya están a nuestro alcance en ediciones actuales, y contribuir a que Fernández Ramírez ocupe en nuestras aulas de Filología el lugar que su investigación linguiística y pedagógica se merece. Resumiré solamente los libros y los artículos y dejaré de lado sus reseñas y traducciones. Me 
referiré a los textos con el número de la ficha, el título y el año - se entiende que las fichas con año posterior a 1983 son ediciones actuales, ediciones póstumas-, pero no repetiré todos los datos bibliográficos salvo si lo considero pertinente para alguna ficha concreta. El lector los podrá encontrar, si los necesita, en el texto, del Boletín de la Real Academia Española, «Bibliografía de Salvador Fernández Ramírez (1896-1983)».

\section{LIBROS Y ARTÍCULOS}

1. Edición y prólogo (págs. 9-19) de Pastores de Belén, de Lope de Vega (Madrid: Editorial Renacimiento, 1930).

Es una edición escolar con prólogo y notas explicativas. En aquel informa sobre las ediciones que ha tenido la obra, sitúa esta en la producción lopesca no dramática, elucubra sobre el estado anímico, espiritual y la presencia de la vida familiar de Lope al escribirla, y analiza la estructura y la presencia de elementos líricos.

4. Edición, prólogo, nota editorial, notas y vocabulario de Instrucción de la mujer cristiana, de Juan Luis Vives (Madrid: Editorial Signo, 1936).

Edita la traducción del latín al romance por Juan Justiniano (Valencia, 1528) siguiendo la edición de Zaragoza (1539). Incluye setenta y siete notas que procuran aclarar los pasajes difíciles, los nombres de personas, de títulos y la procedencia de los textos aducidos, además de un vocabulario con setenta y tres términos. En el prólogo presenta el ambiente europeo del Renacimiento y la Reforma y los rasgos de la personalidad de Juan Luis Vives y los problemas morales, religiosos y literarios de los que se hizo eco el gran humanista.

6. «Retórica y soborno» (La Gaceta Regional [Diario Nacional de Salamanca], 7 de julio de 1938, pág. 1).

Expresa sus preocupaciones como educador en un momento tan dramático para España. Propone que se pase del concepto de los sofistas sobre la Retórica como «arte de engañar» al ideal de educar con «arte de prudencia». 
15. Redacción de artículos (ochenta y nueve entradas) sobre términos de retórica y poética para el Diccionario de literatura española, dirigido por Germán de Bleiberg y Julián Marías (Madrid: Revista de Occidente, 1949; ahora en Madrid: Alianza Editorial, 19724). Cada artículo se cierra con las iniciales S.F.R.

Redactó estos ochenta y nueve artículos en 1941 en función de las directrices marcadas por los directores de este diccionario, Julián Marías y Germán Bleiberg, quienes asignaron las entradas relacionadas con la Retórica, Poética y Métrica a Fernández Ramírez, Germán Bleiberg (321 entradas) y María Josefa Canellana (90 entradas). La mayoría de las entradas escritas por Fernández Ramírez son conceptos de Retórica, aunque no exclusivamente (alegoría, anacoluto, barbarismo, catacresis, enálage, hipérbaton, ironía, metonimia, paragoge, pleonasmo, sinéresis, solecismo, zeugma...). Su método de redacción incluye la etimología de cada término y su historia en la tradición retórica, la definición, ejemplificación en griego, latín o español y datos eruditos bibliográficos. Entre sus materiales inéditos don José Polo encontró unas cuarenta fichas con otros términos de Retórica no incluidos en esta obra.

\section{Lengua literaria y norma lingüística (Madrid: RAE, 1960).}

Es su discurso de ingreso en la Real Academia Española. En él precisa el concepto de norma lingüística en tres sentidos diferentes: como las leyes internas del idioma, estas son las que trata de descubrir el gramático; como modalidad linguíística, los llamados usos cultos frente a usos populares, esta es la que persigue el escritor, en ella la lengua escrita y la literaria superan como ideal a los otros niveles de lengua hablada; como preceptos o reglamentaciones, es el que más interesa al nativo que quiere perfeccionar su conocimiento de la lengua o al extranjero que quiere aprenderla y a los «preceptistas», que se ocupan solo de imponerla. Acaba con la caracterización y una encendida defensa de la lengua literaria.

26. «Los catedráticos de Instituto y la Real Academia Española» (en Cátedra 1960: prontuario del profesor, Madrid: MEC, 1960, 387396).

Breve biografía en lo referente a la elección como Académicos de la Lengua de nueve profesores de Instituto: Francisco Commelerán y Gómez (1903), Manuel de Sandoval (1919), Vicente García de Diego (1926), Antonio Machado (1927), Enrique Díez Canedo (1935), Eugenio Montes (1940), Narciso Alonso Cortés (1945), Gerardo Diego (1947), y él mismo (1959). Aparece una fotografía de alguno de ellos. 
30. «Para la futura Gramática: I. El acento ortográfico. II. Morfología. Generalidades» (Boletín de la Real Academia Española, XLIV/1964, 431-439; 439-448).

Presentó estas dos ponencias en nombre de la Academia Española al IV Congreso de Academias (Buenos Aires, 1964). En la primera se ocupa de las reglas de acentuación en la escritura (con tilde o sin ella) para las palabras esdrújulas, graves, graves con hiato inverso o normal, agudas, agudas en diptongo y en hiato inverso, palabras monosilábicas, patronímicos de fonética no castellana, nombres propios extranjeros, cultismos latinos, palabras con tilde diacrítica, compuestos y verbo con pronombre enclítico. Estas reglas respetan las «Nuevas Normas de Prosodia y Ortografía» (1959) y se incluyen, aunque con otro orden, en el Esbozo de una nueva gramática de la lengua española (1973), apartado 1.8.3. Para la II parte véase ficha 46.

32. «Américo Castro y España» (Papeles de Son Armadans, XXXVII-110/1965, 131-133).

Fue su colaboración a Breve encuesta española, volumen ideado por C.J. Cela como Homenaje en los ochenta años de Américo Castro. Destaca en La realidad histórica de España el objetivismo y el amor de conocimiento con que accede a nuestras contradicciones históricas.

33. «Forma y sustancia líricas» (en la obra colectiva Elementos formales en la lírica actual, Santander-Madrid: Universidad Internacional Menéndez Pelayo, 1967, 47-54).

Es la ponencia que presentó (agosto de 1966) en la Universidad Menéndez Pelayo de Santander al simposio sobre la lírica moderna o poesía en verso libre en el que intervinieron poetas, críticos y linguiistas. Plantea el problema de las relaciones forma-contenido en la literatura y especialmente en la lírica para intentar descubrir si hay formas específicas para verso y para prosa o si hay cambios sustanciales en las formas cuando aparecen en verso o en prosa. Ejemplifica el problema con versos métricos y amétricos en poemas de Cernuda donde observa el uso de la anteposición del complemento objeto no motivada por razones gramaticales necesarias, uno de los tipo de hipérbato más retórico, sino como forma que mantiene la integridad de una estructura métrica clásica; su supresión crearía un verso amétrico.

35. «Cuatro capítulos de fonología» (Boletín de la Real Academia Española, XLVIII/1968, 419-479). 
Estos cuatro capítulos pasan íntegros y con muy ligeras variantes al Esbozo (1973) (1.1. Generalidades, 1.2. Clases de sonidos, 1.3. Clases de fonemas, 1.4. Sílaba). Representan la parte más novedosa e innovadora de esta Gramática al introducir las aportaciones más seguras de la Fonología y de la Fonética en su aspecto articulatorio. En el primer capítulo se define el signo lingüístico oral con su significante y significado, el grupo fónico, las pausas normales y virtuales, los prosodemas, la articulación, el sonido como unidad del habla, la clase de sonido (= fonema) como unidad de la lengua, la sílaba y sus componentes (cabeza, cima, coda), el acento y el objeto de estudio de la Fonética y Fonología. En el capítulo II describe articulatoriamente los sonidos del español en función de los órganos activos, pasivos y modos de articulación, clasifica los sonidos consonánticos en obstruyentes (oclusivos, africados, fricativos) y sonantes (líquidos vibrantes y laterales, nasales, con deslizamiento) y describe cada sonido según las posiciones en las que puede aparecer, ejemplificando con transcripción fonética. Hace lo mismo con los sonidos vocálicos: posición de la lengua y de los labios, resonador predominante, nasalización, vocales silábicas y vocales no silábicas. El capítulo III define los principales conceptos de Fonología: distribución complementaria, variación libre, contraste, fonema, variante combinatoria o alófono, neutralización y archifonema o arquifonema. Define también los fonemas consonánticos y vocálicos del español con sus correspondientes alófonos y los transcribe fonéticamente. Presenta la organización del sistema fonológico con sus varios subsistemas. En estos dos capítulos la norma descrita tanto fonética como fonológicamente es la del español castellano, pero se hacen observaciones en notas o incluso en el cuerpo del texto a las variantes existentes en otros dominios del español. El capítulo IV describe la sílaba en la unidad palabra según las posiciones inicial, interna y final: coda simple y compuesta, cabeza simple y compuesta, fórmulas y leyes de delimitación o frontera silábica (V.V; C.C; V.C), cima silábica y delimitación silábica entre vocales contiguas (diptongos, triptongos, hiatos).

38. «Ortega y Gasset, escritor» (1983).

Este texto pudo haber sido compuesto entre 1957 y 1960 y se leyó, como texto escrito, en los Cursos de Estudios Hispánicos de Soria en 1977, según opinión autorizada de José Polo, quien lo ha publicado en el Boletín de la Real Academia Española (LXIII/1983, 173-225).

Fernández Ramírez examina en la perspectiva literaria y lingüística la obra filosófica de Ortega y Gasset para caracterizarlo como uno de 
los pocos grandes escritores españoles de este siglo. Demuestra con ejemplos orteguianos de metáforas, de periodos, de aptitudes ante el neologismo, el extranjerismo y la paronomasia, de elección ante formas concurrentes, que su prosa es exacta, precisa y bella. Observa, y lo confirma con abundante ejemplificación, que Ortega se consagra como artista de la pura creación literaria en las descripciones y narraciones enclavadas en el cuerpo de sus escritos sin nexo aparente con el contexto.

39. Gramática española. 1. Prolegómenos (Madrid: Arco/Libros, 1985).

Este volumen inexistente en la edición de 1951, preparado por José Polo, recoge en la Primera Parte (capítulos II-VI) juicios críticos (reseñas periodísticas y recensiones analíticas) que ha recibido esta obra y recopila en la Segunda Parte (capítulos VII-XII) la fundamentación teórica y metodológica de su Gramática española. Aquí se ve perfectamente la influencia del Círculo Lingüístico de Copenhague (Hjelmslev sobre todo) y de la Escuela de Praga en nuestro autor. Pero también otras presencias importantes como las de Bühler y Bloomfield, por citar solo a dos figuras señeras de la Linguística. La Tercera Parte (capítulos XIII-XV), además de notas de sus lecturas de Charles F. Hockett y Zellig Harris y notas de clase tituladas «La categoría de pronombre», incluye en el capítulo XII, páginas 237-256, el texto «El concepto de forma en gramática» (1958, ficha 21).

Este artículo fue su contribución al número monográfico de la Revista de la Universidad de Madrid (VII-26/1958, 161-173 para el texto de Fernández Ramírez) titulado El concepto de forma en la ciencia moderna. Nuestro autor parte de Saussure: la combinación significante-significado produce una forma, no una sustancia. Pero retrocede al siglo XIX, donde encuentra la idea de forma, usada en Morfología (= miembro de un paradigma flexivo $=$ accidentia) y en Fonética Histórica o Linguística Comparada (= variaciones de la palabra en la historia del idioma). Continúa con el valor de forma (= morfema, morfémica, morfemática) para el estructuralismo de Copenhague: forma del contenido y forma de la expresión (Hjelmslev), sustancia del contenido y sustancia de la expresión (Trubetzkoy). La aplicación al campo fonético supuso la aparición de la Fonología, a pesar de que la palabra forma no aparece ni una sola vez en los Principios de fonología de Trubetzkoy. Y su aplicación al campo de la morfología y de la sintaxis supuso el desarrollo del formalismo en la investigación lingüística, la gramática formal: Escuela danesa de Hjelmslev o norteamericana de Bloomfield. 
Acaba el volumen con una Cuarta Parte (capítulos XVI-XVII) con el «Prólogo» a la edición de 1951 y «Prólogo complementario», texto inédito y escrito probablemente hacia 1961, pues alude a «al cabo de diez años» (página 312), en el que habla de la organización de los volúmenes que faltan para completar su gramática y de la urgencia de prepararlos para la imprenta.

40. La enseñanza de la gramática y de la literatura (Madrid: Arco/Libros, 1985).

José Polo publica esta recopilación de trabajos editados (los de las fichas 8: capítulo IV, 23a: capítulo V, y 26a: capítulo VI) e inéditos (los demás), que representa a la perfección las preocupaciones y las propuestas didácticas del autor en el campo de la enseñanza, en sus diferentes niveles docentes, de la Lengua y de la Literatura española y latina, a la que se dedicó con pasión desde 1933 (también a la enseñanza de griego).

El capítulo I «Instrucciones metodológicas para la enseñanza del latín», redactado posiblemente entre 1937-1939 (1937: profesor de Lengua Latina en el Instituto de Plasencia (Cáceres); 4-11-1939: Lope de Vega, Madrid), es una programación o proyecto docente según un procedimiento analítico para los seis cursos del Bachillerato de entonces. Destaca la división en dos ciclos de tres años, la graduación en oraciones y en textos, en morfología y sintaxis, la traducción directa e inversa, en prosa y verso, la comparación entre la gramática latina y la española, entre el léxico latino y el español.

El capítulo II «Instrucciones metodológicas para la enseñanza del español», redactado posiblemente entre 1933-1938 (1-11-1933: profesor de Lengua y Literatura española en el Instituto de Miranda de Ebro (Burgos); 13-10-1938: Instituto de Salamanca), es una programación para los siete cursos de Lengua española del Bachillerato de entonces. $\mathrm{El}$ objetivo fundamental reside en cultivar la capacidad expresiva del hablante nativo y enriquecer sus posibilidades expresivas. Las actividades básicas en clase serán el comentario de textos y la composición de textos. Las fases del comentario de textos incluyen: comprensión del contenido, intención del autor, género y estilo, partes, examen lexicográfico y lexicológico (familias léxicas, sinonimia, niveles léxicos, derivación y composición, tropos y figuras). Describe los ejercicios de composición literaria y no literaria o ensayística y el método de corrección de las composiciones en clase para conseguir mayor eficacia. Defiende que la enseñanza de la gramática debe concebirse como 
bloque aparte y con horario aparte, y más reducido que el que se dedicará a las actividades descritas más arriba.

El capítulo III «Metodología de la enseñanza de la Lengua y Literatura española», redactado por las mismas fechas que los dos anteriores, son reflexiones más elevadas y apoyadas en bibliografía explícita en la línea de los Proyectos o Memorias docentes conocidos como «concepto y método de la signatura». Así lo revelan los epígrafes «La Literatura como ciencia desde el Renacimiento hasta nuestros días», «La metodología de la enseñanza de la Literatura», «La metodología de la enseñanza de la lengua española». Destaca en este texto su defensa de no escindir el estudio de la lengua y de la literatura y su justificación para no confundir enseñanza de la lengua con enseñanza de la gramática.

El capítulo IV «Enseñanza de la gramática y de la literatura» recoge el opúsculo de 38 páginas escrito en 1936 y publicado en 1941 (ficha número 8). Representa el pensamiento de su autor en esta zona de encrucijada de la linguística, la ciencia literaria y la pedagogía. Desarrolla ideas pedagógicas interesantes en diferentes epígrafes como «Didáctica del lenguaje», en el que denuncia la escasez de libros programados gradualmente para una didáctica eficaz del idioma en los ciclos de primaria y secundaria (habla de la década de los años cuarenta); como «Enseñanza del lenguaje» o «Categorías gramaticales» en los que demuestra que el aprendizaje de una lengua no implica necesariamente el conocimiento de la gramática de esa lengua, en consecuencia las actividades en clase deben ir encaminadas al examen literario de textos o a ejercicios idiomáticos orales y no al conocimiento de conceptos gramaticales, a distinciones entre hechos de lengua hablada y lengua escrita con sus anomalías de correspondencia en cuanto a unidades como letras, sonidos, sílabas, palabras, a gradaciones en los hechos linguísticos que lleven después y escalonadamente a conceptos gramaticales y no al revés; como «El conocimiento del idioma. Lengua y literatura» en los aspectos interpretativos y creativos mediante estudio de los textos literarios, lectura en clase, recitación oral, composición escrita porque la enseñanza de la lengua no puede separarse de la enseñanza literaria; la lectura de un texto debe ir seguida de ejercicios complementarios sobre él: narrar oralmente un pasaje, explicar significados, ordenar el relato, observar familias lingüísticas, resumir por escrito, componer textos. Acaba con reflexiones sobre el método ideal de corregir textos de los alumnos para conseguir más eficacia: la corrección de textos debe hacerse anónima pero públicamente en la 
pizarra, ante todos y con la colaboración de todos, también resulta muy útil la composición colectiva de un texto. Selección de lecturas literarias para la escuela según las aportaciones de la psicología infantil y juvenil. El propone: ciclo épico de la Antigüedad y Edad Media, ciclo mítico de los clásicos, epopeya española, romancero, ciclo teatral en el que se desarrolla la épica y el romancero, libros de caballerías, crónicas de los conquistadores, colecciones de apólogos. Acaba con una bibliografía comentada en la que aparecen los nombres de Rafael Seco, Federico Hanssen, R. Menéndez Pidal, Jaime Oliver Asín, Rodolfo Lenz y Manuel de Montolíu, y ediciones de lectura recomendables.

El capítulo $\mathrm{V}$ «Consideraciones didácticas sobre la lengua y el habla desde el punto de vista de la Escuela Primaria» (Vida Escolar [Madrid], 15-16/1960; ficha 23a) es un conjunto de orientaciones sobre cómo debe ser un buen manual de lengua para la Escuela Primaria. En él no puede faltar el estudio del léxico a partir de los índices de frecuencia y vocabularios mínimos, la polisemia, la derivación y composición, pero sin desligar las palabras de sus contextos, sus construcciones y su régimen. También hay que atender al material de lectura: narraciones, romances, breves canciones líricas de los clásicos y de los modernos, fábulas, que permitan ejercitar la memoria. Se completaría con actividades que relacionen la corrección de vicios de la pronunciación con la ortografía y la caligrafía. La enseñanza de la gramática se reduciría en este nivel a aspectos normativos. Todo ello graduado según edades y cursos. Acaba con una noticia bibliográfica sobre libros recomendables (T. Navarro Tomás, M. Muñoz Cortés, E, Lorenzo, S. Gili Gaya, J. Casares, Laura Brackenbury, Concepción Sáiz, D. Tirado, R. Seco, E. Sapir) con los que el maestro podrá preparar sus clases de lengua española hasta que se publiquen manuales como el descrito tan sucintamente por Fernández Ramírez.

El capítulo VI «Palabra y música» (Servicio, XIV-735/1960; ficha 26a), tras unas reflexiones sobre el papel que la entonación y las figuras tonales desempeñan en la lengua para la exacta comprensión de los mensajes orales, plantea la cuestión del lugar que debe ocupar en la enseñanza primaria de la lengua el fenómeno de la entonación. Responde que ninguno. Sugiere que se reduzca a un simple ejercicio de imitación guiado por la voz del maestro, como autoridad ejemplar en los aspectos sonoros de la lengua.

El capítulo VII «Redacción y método. Primera lección» es una lección magistral de un curso o asignatura que Fernández Ramírez profesó durante varios años (1951-1955) en la Escuela Superior del Aire, 
Madrid. En este texto se trata el problema de la redacción integrada en su contorno estilístico y retórico: la lectura de obras literarias, qué se entiende por norma en el hablar y escribir, cómo se relaciona la actividad de escribir con la de leer, entender e interpretar un texto. Predomina en él un enfoque humanístico, gran riqueza conceptual y elegancia en la expresión. Recuerda una experiencia personal: los cursos intensivos de comentario de textos literarios y prácticas de redacción para los alumnos de los primeros años de la Facultad de Filosofía y Letras (Universidad Complutense de Madrid) con los que se completaba la formación literaria y linguiística de los alumnos de Bachillerato. Lástima que no exista hoy día algo parecido en las Facultades de Filosofía y Letras de nuestras Universidades, a las que llegan miles de estudiantes con ortografía deficiente y pobreza de léxico y de sintaxis.

41. Gramática española. 2. Los sonidos (Madrid: Arco/Libros, 1986).

La primera parte de la edición de 1951 (ficha 18) pasa a este volumen, editado por José Polo, con cinco capítulos (Las unidades fónicas. La palabra aislada y la delimitación silábica. Los sonidos en la cadena sonora de la oración; subordinación acentual y melódica. El origen de los sonidos. Función diacrítica y simbólica de los sonidos) y un apéndice del editor, más 157 notas a pie de página; las del compilador aparecen con el número encorchetado. Se mantiene la numeración antigua de los párrafos, pero se crean subpárrafos numerados. En el prólogo de 1951 proclamaba su deuda en cuanto a la fonética que aquí expondrá «sin apartarme un punto de la doctrina española tan sólidamente establecida por la escuela de Tomás Navarro». Pero su modestia no debe ocultar las innovaciones que introduce y los aciertos que logra; por ejemplo, en cuanto a la delimitación silábica y a las continuas referencias a la fonética histórica del español, además de la aplicación de los elementos entonativos a cuestiones gramaticales como la posición del adjetivo, las oraciones de relativo y las oraciones interrogativas que hará en otros volúmenes.

42. Gramática española. 3.1. El nombre (Madrid: Arco/Libros, 1986).

Aquí incluye José Polo la segunda parte de la edición de 1951. Este primer volumen del tomo tercero se ocupa del nombre sustantivo y del nombre adjetivo y consta de dos capítulos (El nombre. Género y número del nombre) y 409 notas a pie de página, las del compilador 
encorchetadas. La inspiración de esta gran obra está en la gramática inglesa de Otto Jespersen, A Modern English Grammar on Historical Principles (comenzó su publicación en 1914), de la que toma la organización fundamentalmente categorial, pero añadiendo una exhaustividad descriptiva nunca alcanzada en ninguna otra gramática del español. Aquí combina perfectamente sincronía y diacronía, conocimiento del latín y del español, descripción morfológica, sintáctica y semántica.

43. Gramática española. 4. El verbo y la oración (Madrid: Arco/Libros, 1986).

Este volumen, inexistente en la edición de 1951, contiene un minucioso análisis de la categoría verbo distribuido en once capítulos inéditos, salvo lo que se indica más adelante: Las personas gramaticales. Los complementos del verbo: el complemento directo. Los tiempos verbales. Los modos verbales. Los verbos reflexivos y la voz media. El participio y las formas pasivas. El orden de las palabras: la posición del sujeto. Las oraciones interrogativas (repite el trabajo de 1959, ficha 22). Las oraciones nominales; y dos apéndices que recogen los trabajos de 1937 «Como si + subjuntivo» (ficha 5) y 1960 «Algo sobre la fórmula estar + gerundio» (ficha 23). Gran parte de estos materiales fue elaborada en los años cuarenta y cincuenta. Ignacio Bosque explica en el Prólogo su intervención al prepararlos para la imprenta.

«Oraciones interrogativas españolas» (Boletín de la Real Academia Española, XXXIX/1959, 243-276; ficha 22) es ahora el capítulo X. Fernandez Ramírez resume los objetivos de este artículo así: «[...] componer un cuadro sumario de las frases interrogativas españolas, tratando de apoyarme para ello, por un lado, en sus caracteres formales y tonales, y por otro en los supuestos situacionales e intencionales de que son correlato. En segundo lugar, me proponía muy especialmente realizar una especie de ajustamiento con la ciencia de la fonética desde el campo de la sintaxis, dentro de este reducido territorio de la interrogación» (vol. 4, pág. 463-464).

Trata de aplicar la descripción que hizo Tomás Navarro Tomás en su Manual de entonación española (1948) de los tipos principales de oraciones interrogativas en función de las curvas melódicas -inflexión inicial, cuerpo e inflexión final-, en las que el tonema o inflexión final es el determinante para la clasificación: Interrogación absoluta (IA: en Anticadencia), Interrogación aseverativa (IC: en Cadencia), Interrogación continuativa (Is: en Circunfleja), Interrogación relativa 
(Ir: en Circunfleja), Interrogación intensificativa o exclamativa (Ie: en Anticadencia). Fernández Ramírez describe estos tipos de interrogativas según sus diferentes valores expresivos e inflexiones finales: las preguntas inquisitivas (interrogación absoluta en Anticadencia) con no/(pero) no/sin partícula negativa, las preguntas reflejas (interrogación relativa con inflexión circunfleja), las preguntas disyuntivas (Anticadencia + Cadencia), las preguntas exploratorias (Anticadencia + Cadencia; otras, circunfleja; otras, Anticadencia), las diferentes preguntas pronominales (paradójicas, enigmáticas, dubitativas y evocadoras) con Cadencia, también con Anticadencia y también con Circunfleja, las preguntas exclamativas (de contradicción y de repulsa) ahora sin referencias explícitas a sus variados tonemas finales. Toda la descripción va acompañada de abundantísima ejemplificación literaria analizada con gran finura interpretativa, pero en la que el lector puede quedar perdido ante tanta variedad.

«Como si + subjuntivo» (Revista de Filología Española, XXIV/1937, 372-380; ficha 5) se incluye como apéndice I, páginas 523-530.

Fue su primer trabajo gramatical publicado. Analiza los valores semánticos de las construcciones con como si y subjuntivo irreal para establecer las principales categorías y caracterizar las más importantes. Primero presenta las fórmulas que poseen un valor descriptivo y metafórico ( «Tocaba sus gestos como si tocase su alma desnuda») con las que el hablante corrobora la realidad presuntiva o conjeturalmente (lo llama uso presuntivo o de conjetura: «Y estas lilas, como si lo viera, serán de alguna propiedad de usted, de alguna casa de campo») o se presenta ante ella dispuesto a aceptarla (lo llama uso imperativo o ético o cualificante: « ¿De modo que no hay que contar con esa gente? - Como si no existieran»). Después analiza las fórmulas que expresan la anomalía de una conducta en relación con las circunstancias en que se produce (lo llama uso anómalo o paradójico: «El supremo actor trataba a sus subalternos como si fueran chiquillos de escuela», de él procede el uso exclamativo con significado de negación indignada o repulsa: «Como si la señorita Ángela tuviese la culpa de que el señor Conrado esté loco de amor por ella»). Concluye apuntando otras fórmulas sintácticas que pueden alternar o sustituir a las aquí descritas para expresar sus mismos valores semánticos: como + relativo + indicativo: «Lo hizo como el que lo sabía bien», relativo + subjuntivo irreal metafórico: «Parecía emitida por una avecilla que se remontara primero al cielo», sustantivas subordinadas dependientes de parece que con indicativo/subjuntivo: «Todo el pueblo, todos los árboles, 
todas las gentes parecía que perteneciesen [pertenecían] a la heredad de Nuestro Padre».

«Algo sobre la fórmula estar + gerundio» (en Studia Philologica. Homenaje ofrecido a Dámaso Alonso por sus amigos y discípulos con ocasión de su $60^{\circ}$ aniversario, Gredos, Madrid, I, 1960, 509-516; ficha 23) aparece como apéndice II, páginas 531-539.

Tras unas reflexiones sobre la metodología en el análisis de cuestiones gramaticales y los valores semánticos de estar, examina las combinaciones de este verbo como auxiliar en las perífrasis con gerundio. Constata su combinación con verbos de lengua (cantar, hablar, decir, contar, charlar, discutir, gritar), de acción en movimiento (coser, escribir, jugar, guisar, limpiar, trabajar, bailar) o en reflexión (pensar, meditar, leer, mirar, soñar) y con sujeto humano y el rechazo casi total de la negación en estas perífrasis. Cree que el concepto de 'duración' que todos los gramáticos han señalado en esta perífrasis no es su elemento definidor y lo demuestra comprobando el contraste señalado por él en La colmena, de C.J. Cela, donde observa que aparece dos veces estar diciendo frente a 203 veces otras formas del verbo decir. Para Fernández Ramírez el elemento semántico definidor de estar + gerundio es la expresión de momentos perceptivos.

44. La derivación nominal (Anejo XL del Boletín de la Real Academia Española, Madrid: RAE, 1986).

Fernández Ramírez llevaba varios años preparando materiales sobre formación de palabras destinados a ser publicados como volumen complementario del Esbozo, pero no pudo concluir su elaboración. Ignacio Bosque ha publicado la parte redactada por nuestro gramático referida exclusivamente a la derivación nominal. Se trata de la descripción de ciento diez sufijos con los que se crean nombres y adjetivos (Ignacio Bosque deja fuera otros setenta y seis por no contar con redacción previa). La descripción establece una clasificación según la estructura fonética: sufijos formados exclusivamente por una o más vocales (-a, -e, -o, '-eo, -ea, -io, -ia, -uo, -ua, -ue, -éo, -ía, -ío); sufijos que terminan en vocal no precedida por dos consonantes (-aco/-ico/ -uco, -íaco/-aco/-co, -ico, -icial-icie/-icio, -ucho, -ada, -ado, -edo/a -ido/a, -ido/'-ido, -udo, -ago/a, -igo/a, -ego, -iego, -ugo/a, -ajo, -aja, -aje, -ejo/a, -ijo/a, -ojo/a, -ujo/a, -elo/a, -uelo/a/-zuelo/a-lezuelo/a, -culo/a, -illo/a/-cillo/a, -amo/a/-iano/a, -aina, -eno, -ina, -ino, -ón/a, -eñol-ueño, -uño, -erola, -dero/a, -era, -orio/a, -ario, -aria, -ería, -erio, -uro, ura, -uría, -osola, -uosola, -esal-isa, -ata, -ate, -ete, -ato, 
-ote/a, -ito/a, -ivo/a, -azo, -izo/a); sufijos acabados en vocal con dos o más consonantes delante (-ble, -ense/-iense, -ante/-ente/-iente, ancial -encia/iencia, -mento/-miento, -menta/-mienta, -lento/iento, iento/a, -esco/a, -usco/-uzco); sufijos terminados en consonante (-dad, -tad, -tud, -al, -il, -in/a, -ón/a, -ción, -ar, -or, -és, -az, -ez/a, -iz). Además para cada sufijo aporta la categoría gramatical del resultado (sustantivo o adjetivo), la categoría gramatical de la base latina o romance, el significado o los significados y el índice de productividad.

45. Gramática española. 3.2. El pronombre (Madrid: Arco/Libros, 1987).

Este segundo volumen del tomo tercero, editado por José Polo, recoge la tercera parte de la edición de 1951 (ficha 18). Consta de una Introducción: Consideraciones generales sobre los pronombres, y cuatro capítulos: Pronombres personales. Los pronombres demostrativos y el artículo. Pronombres interrogativos, relativos y exclamativos. Pronombres indefinidos, cuantitativos y numerales; más un apéndice que recoge el texto de 1964 «Un proceso lingüístico en marcha» (ficha 31) y 972 notas a pie de página. Este volumen constituye el tratado más completo que se ha escrito sobre los pronombres en el español.

«Un proceso lingüístico en marcha» (Presente y futuro de la lengua española, Instituto de Cultura Hispánica, Madrid, 1964, II, 277-285; ficha 31) aparece como apéndice I, páginas 391-405. Examina las vacilaciones entre diversas formas y funciones del pronombre objeto $l e(s), l o(s), l a(s)$, del complemento con $a$, de las construcciones con $s e$, procesos gramaticales que considera ligados entre sí y determinados por la necesidad de marcar claramente la distinción de persona y cosa. También alude, aunque brevemente, a una sustitución paulatina de ser por estar (lleno/contento/feliz).

46. La nueva gramática académica. El camino hacia el «Esbozo» (1973) (Madrid: Paraninfo, 1987).

El núcleo de esta obra editada por José Polo recoge varios trabajos de Fernández Ramírez (fichas 24, 30, 34 y 36) para la redacción del Esbozo de una nueva gramática de la lengua española (1973). En este libro queda patente la generosidad intelectual de Fernández Ramírez, quien puso su inteligencia al servicio de la Docta Institución sacrificando su obra personal. Incorpora el libro dos trabajos más: «A propósito de los diminutivos españoles» (1962, ficha 29) y «Derivados españoles en -ivo» (1975, ficha 37). 
Los capítulos I (págs. 13-18) y IV (págs. 41-57) recogen el texto de 1960 «La revisión de la Gramática de la Academia Española. El pronombre» (Tercer Congreso de Academias de la Lengua Española. Actas y labores, Academia Colombiana de la Lengua, Bogotá, 1960, 399-420; ficha 24).

Es una muestra del nuevo texto que la RAE venía preparando desde que recibió el encargo en el Segundo Congreso de Academias (1956) de revisar el texto de la Gramática académica (1931). Allí se había acordado renovar y remozar la doctrina e introducir puntos de arranque sistemáticos. Al mismo tiempo se había considerado conveniente no encajar el estudio del español en el esquema teórico de ninguna escuela. El presente anticipo revisa el capítulo IV de la primera parte de la Gramática, el del Pronombre. Expone las dificultades de distribución y de construcción de los pronombres así como una caracterización de los pronombres y de sus subcategorías atendiendo a las funciones gramaticales específicas y a los datos casi exclusivamente formales de cada uno. Justifica la introducción de términos como deíctico, anafórico, neutralización, sincretismo, signo cero. Desarrolla los siguientes epígrafes: «Consideraciones generales sobre los pronombres, Pronombres personales, Pronombres posesivos, Mismo, Pronombres demostrativos, Pronombres relativos, Pronombres interrogativos y exclamativos, Pronombres indefinidos», siguiendo la ruta de la Gramática de 1931 (capítulo IV, Del pronombre, \& 69-76). El resumen que aquí ofrece Fernández Ramírez se desarrolla en el Esbozo (1973) en cinco capítulos del 2.5 al 2.9, páginas 202-248, con una versión bastante distanciada de la aquí expuesta.

El capítulo 2 (págs. 19-32) incluye el texto de 1968 «Anticipos de la nueva Gramática» (en Boletín de la Real Academia Española, XLVIII/1968, 401-417; ficha 34).

En este artículo pasa revista a las directrices expuestas por Rafael Lapesa (1956) para la reforma de la Gramática académica (1917, $1920,1931)$ con el fin de que se vea cómo han sido mantenidas en la concepción del plan o cómo han sido ligeramente modificadas en algunos casos. Expone las soluciones dadas al problema de la terminología linguística, al carácter normativo y a la ejemplificación basada en autoridades literarias del pasado y del presente peninsular e hispanoamericano, a las partes de que constará la nueva Gramática -Fonología, Morfología y Sintaxis - y a los contenidos que incluirán, a los criterios para definir las unidades o categorías lingüísticas y sus funciones. 
El capítulo 3 (págs. 33-38) recoge el texto inédito «La Academia y la nueva edición de su Gramática» (1971, ficha 36).

Texto dirigido a los asistentes al II Congreso Internacional para la Enseñanza del Español (Madrid, 1971). Esto determina una selección de los aspectos que va a desarrollar en su comunicación Fernández Ramírez para adecuarla al temario del Congreso. Justifica la necesidad de reformar la vieja Gramática académica, proceso ya prácticamente concluido en 1971 tras varios años de trabajo en la Comisión de Gramática de la RAE, y resume las innovaciones más importantes. En los capítulos de Fonología: la descripción articulatoria y distribucional de sonidos y fonemas, la noción de sílaba y el límite silábico, el acento prosódico y el no acento. Justifica la adopción de tecnicismos como alófono, deíxis, deícti$c o$, la supresión de términos como ablativo, dativo, acusativo en el paradigma del pronombre personal así como toda la flexión casual del nombre, y otras modificaciones de menor importancia en la flexión verbal como sustituir pretérito indefinido por perfecto simple o introducir perfecto compuesto o incluir el condicional en el modo indicativo o la terminología de Bello junto a la de la Academia para los paradigmas verbales. Y explica la exclusión del yeísmo y del seseo y de otros patrones tonales a pesar de su mayor extensión diatópica en el mundo hispanohablante.

El capítulo 5 (págs. 58-66) incluye la II parte del texto de 1964 «Para la futura Gramática: I. El acento ortográfico; II. Morfología. Generalidades» (en Boletín de la Real Academia Española, XLIV/1964, 439-448; ficha 30).

Presentó estas dos ponencias en nombre de la Academia Española al IV Congreso de Academias (Buenos Aires, 1964). En la segunda ponencia define y ejemplifica los conceptos fundamentales de la Morfología en cuanto a la segmentación y taxonomía de sus unidades: forma lingüistica, forma libre, forma compleja, forma simple (morfema), forma exenta y forma trabada, palabra, palabra independiente y dependiente, radical, morfemas derivativos (sufijos), morfemas flexivos (desinencias), base, tema, desinencia, raiz o radical. Presenta problemas generales como: variaciones en los morfemas radicales y flexivos, doble valor de los morfemas diminutivos, concepto de derivación y composición (composición propia, impropia, yuxtapuesta, endocéntrica, exocéntrica) con sus diferentes relaciones semánticas; en los compuestos incluye también la prefijación, la combinación de temas y raíces grecolatinas y la parasíntesis. Analiza el acento en los compuestos y en los grupos sintácticos. El texto ofrece una versión algo distanciada de la que apareció finalmente en el Esbozo (2.1.). 
El capítulo 6 «Terminología» (págs. 67-72) incluye un texto inédito (1969) de su correspondencia científica con Samuel Gili Gaya, el otro redactor fundamental del proyecto que acabó como Esbozo (1973), sobre algunas cuestiones terminológicas: acuerdo en suprimir el modo potencial, pero manteniendo la palabra condicional u optativo; acuerdo en considerar la voz pasiva o construcción pasiva como componente de la sintaxis, no de la morfología; acuerdo en hablar de formas no personales; propuestas para nomenclatura de tiempos verbales: suprimir lo de pretérito indefinido y ordenar todo el paradigma de los tiempos simples y compuestos; preferencia por el término predicativo sobre atributivo en las construcciones con verbo copulativo; dejar como únicas formas del imperativo ama y amad; preferencia por artículo determinado mejor que definido.

El capítulo 7 (págs. 75-84) recoge el texto de 1962 «A propósito de los diminutivos españoles» (en Strenae. Estudios de filología e historia dedicados al profesor García Blanco, Universidad de Salamanca, 1962, 185-192; ficha 29).

En este artículo sale en defensa, aunque sea a contracorriente, del valor semántico de pequeñez implicado en el fondo conceptual de los diminutivos; una lanza a favor de la definición académica de diminutivo en su Diccionario como «vocablos que disminuyen o menguan la significación de los positivos de que proceden». Nuestro autor conoce todo lo escrito en defensa de los valores expresivos, afectivos, apelativos de los diminutivos (Amado Alonso, 1935, Emilio Náñez, 1954), pero lo considera válido para el lenguaje familiar y para la literatura dramática y no para la prosa narrativa, descriptiva, expositiva o doctrinal. En su trabajo aportará numerosos ejemplos sacados de obras de este tipo en los que él sigue viendo como predominante la función representativa de lo «pequeño» o de «pequeñez relativa». Incluye ejemplos de objetos o seres que por su naturaleza son pequeños (miguitas, gotitas, gusanillos, abejicas, olivitas), de individuos pequeños de una especie (nubecita, fueguito, obrita, casilla), de procedimientos ordinarios de derivación que acaba lexicalizándose (mosquito, manguito, manecilla, boquilla, cigarrillo) o sin lexicalización (cuellecito, lucecitas, pequeñito, chiquito, menudito). La expresión de lo dimensional puede hacerse de dos formas: mediante un diminutivo analítico (= pequeño mar, diminutas aldeas) y mediante un diminutivo sintético (= aldeítas), aunque la proporción tan escasa de aquel (11\%) sobre este demuestra que se emplea cuando no es posible elegir este. Sus últimos ejemplos aparecen en la descripción directa y visual del 
paisaje, pues la distancia hace que seres y cosas aparezcan disminuidos (figurillas, barquitos, caminitos, casitas). Así rehabilita Fernández Ramírez la idea de la dimensión en los diminutivos, especialmente en el sufijo -ito.

El capítulo 8 (págs. 85-89) recoge el texto de 1975 «Derivados españoles en -ivo» (en Archivum, XXV/1975. Homenaje a la memoria de Carlos Clavería, I, 1975, 323-327; ficha 37).

Parte de un corpus de 299 formaciones, pero calcula que existan aproximadamente cuatrocientas. Considera este sufijo de plena vigencia actual y de formación muy regular y homogénea. Las bases latinas participiales en -tus, -sus producían adjetivos en -t-ivus, -s-ivus y producen las formas españolas -t-ivo (92 formaciones heredadas), $-s$-ivo (siete formaciones heredadas).

En las 200 formaciones nuevas sigue predominando $-t-i v o$, pero ha aumentado mucho - $s$-ivo (unas sesenta). Las formas nuevas son analógicas de las heredadas: bases en -tus, -sus: coactus $>$ coactivo, aggressus $>$ agresivo, y producen adjetivos con significación activa.

Es excepcional la existencia de otras bases no participiales, latinas o españolas, con final $-t$, $-s$ : cualitat-ivo, substant-ivo, infinit-ivo, inventiva, deport-ivo, fest-ivo, mas-ivo. Y más excepcional la de bases con otro final: gerund-ivo, lasc-ivo.

Algunas formaciones en -ivo/a se han sustantivado (cooperativa, evas-iva, mis-iva) o solo fueron sustantivos (expectat-iva, dativo), pero mantienen la significación activa derivada de su base verbal.

47. Problemas y ejercicios de gramática (Madrid: Arco/Libros, 1987).

B. Palomo Olmos presenta en esta obra materiales inéditos de Fernández Ramírez ordenadas según un criterio gramatical para ofrecer al lector una variadísima serie de actividades lingüísticas sobre signos de puntuación, acentos, pronunciación, género, número, derivación, sintaxis del verbo y del pronombre, léxico y diagnosis gramatical de textos. La propuesta de mejora y de solución junto a cada ejercicio hace más fácil su aprovechamiento aunque no se cuente con la ayuda del profesor de lengua. Desde el punto de vista científico, creo que cabe destacar el capítulo VIII «Mismo anafórico: un pronombre espectacular» por el abundantísimo material que ofrece nuestro gramático. 
Como Apéndice del capítulo XV (págs. 274-278) se incluye el texto «Los libros y la lengua española» (en La Gaceta Regional [Diario Nacional de Salamanca], 30 de abril de 1939, pág. 4; ficha 7). Con ocasión de una Semana del Libro se publicó esta charla radiada en la que se refleja perfectamente su preocupación cultural y humanística. En el texto presenta la lectura como un placer íntimo personal y el libro como guía hacia fuera de uno mismo e invita a un mejor conocimiento del tesoro literario encerrado en nuestros clásicos del que derivará un mejor conocimiento y dominio de nuestra lengua.

48. Gramática española. 5. Bibliografía, nómina literaria e índices (Madrid: Arco/Libros, 1991).

Este volumen, preparado por B. Palomo Olmos, recoge los múltiples datos de referencias bibliográficas y fuentes literarias aparecidas en los volúmenes $2,3(3.1,3.2)$ y $4: 350$ autores y 497 títulos en la bibliografía científica; 564 autores y 1305 títulos en la nómina de fuentes literarias. En el índice analítico aparecen los conceptos, las formas, las fórmulas gramaticales y las voces comentadas por el autor como ayuda para navegantes por esta obra inmortal, obra de estudio y de consulta, no de lectura pasajera.

49. «¿Dónde están las palabras?» (Analecta Malacitana, XVIII$1 / 1995,175-188)$.

Este texto publicado por B. Palomo Olmos es una conferencia inédita de don Salvador en la Escuela Central de Idiomas de Madrid (hacia 1955). Se trata de un texto de carácter divulgativo, ameno y con ejemplificación interdisciplinar que hace intuitiva a un auditorio poco versado en conocimientos de lingüística la comprensión de conceptos abstractos, un texto que combina con gran precisión ideas de Linguíistica General y sus aplicaciones prácticas a la Lengua Española. Fernández Ramírez aprovecha las experiencias personales de los estudiantes de idiomas para llevarlos a reflexiones científicas sobre el lenguaje. Y lo hace adoptando un enfoque formal y estructural con el que determinar la frontera entre palabras - unidad superior al fonemasonido y a la sílaba-, aquella en la que se establece un punto crítico de máxima y mínima probabilidad combinatoria entre fonemas en la palabra según el índice numérico de cada punto crítico. Termina su exposición contrastando el método propuesto por él para aislar la palabra con los métodos tradicionales y con sus aplicaciones al dilucidar si combinaciones como ¿por qué?/porque, se veía/veíase deben considerarse dos o una palabra. 


\section{IMPORTANCIA DE SU GRAMÁTICA}

Por desgracia no ha sido la obra más leída ni la más comentada en las aulas de Filología de la Universidad española, a pesar de que fue recibida por la crítica internacional como una obra maestra, orgullo para la Filología española. Y a pesar de que la segunda edición (Madrid: Arco/Libros) ha permitido que Fernández Ramírez esté más al alcance de la mano, en la calle y en las aulas y no solo en las Bibliotecas, tengo la impresión de que no es la obra que más recomienden a los alumnos los profesores de Lengua Española.

Sin embargo, es la gramática del español más importante y novedosa del siglo XX a pesar de que no pudo ver editada completa su obra, que él había concebido en cuatro volúmenes: (1) los sonidos, el nombre y el pronombre; (2) el verbo, sus clases y complementos, el tiempo, la persona, el aspecto, el modo y las formas nominales; (3) las partículas; (4) la oración y sus clases, la coordinación y la subordinación. Desde hace unos años y bajo la dirección de Ignacio Bosque, J. Antonio Millán y $\mathbf{M}^{\mathrm{a}}$. Teresa Rivero se está trabajando en el Instituto Cervantes en el proyecto AGLE (= Archivo Gramatical de la Lengua Española) para ordenar y editar el fichero gramatical de Fernández Ramírez en CD-ROM y ponerlo al alcance de los investigadores. Y es la gramática más importante no solo por las deudas que tiene con la Lingüística moderna, sino también por las novedades que aporta. Él reconoció su deuda con la gramática inglesa de Jespersen en cuanto a la organización categorial y en cuanto al uso de autoridades linguísticas y la influencia de la escuela danesa y de Bühler, además de la tradición hispánica de Bello, entre otros muchos. Uno de sus objetivos fundamentales consiste en establecer las categorías linguísticas con precisión y con los criterios formales de la lingüística moderna. Eso solo la convierte, sin ninguna duda, en la gramática más científica publicada sobre el español.

Las aportaciones son innumerables. Ignacio Bosque en su discurso de ingreso en la RAE titulado «La búsqueda infinita. Sobre la visión de la gramática en Salvador Fernández Ramírez» (junio 1997) las resume así: el principio de delimitación silábica; la aplicación del análisis entonativo a cuestiones sintácticas como la posición del adjetivo, las oraciones de relativo y en particular las fórmulas perifrásticas, y las oraciones interrogativas; el estudio de los factores pragmáticos que intervienen en la gramática y de aspectos del discurso, a los que él se 
refiere con términos como «contenidos expresivos y apelativos», «actos psíquicos, representativos, volitivos y emocionales»; los campos de sentido, los entes únicos, los factores en la selección del modo, el concepto de genericidad en artículos y pronombres, el concepto de deíxis, ciertos fenómenos de concordancia.

Es una gramática de autoridades por la ejemplificación, pero no es una gramática normativa. De los tres sentidos de norma que maneja Fernández Ramírez (véase ficha 25) interesa aquí el primero: como leyes de la gramática, las que investiga y trata de descubrir el gramático. No son textos de autoridades, sino textos de los que extraer las leyes que gobiernan y rigen la gramática de una lengua. Trabajaba con un archivo, en vez de trabajar con un corpus como hacen los gramáticos actuales. Es cierto que el lector actual, acostumbrado a leer estudios gramaticales modernos elaborados con la técnica de corpus reducidos que ponen en evidencia los contrastes mínimos que el gramático intenta elucidar, puede sentirse desconcertado y perdido ante la abundancia de ejemplificación con la que nuestro autor confirma la descripción gramatical que lleva a cabo. Pero eso no debe ser un obstáculo que nos aleje de la consulta continua de esta obra.

El citado discurso de Ignacio Bosque y las varias ediciones preparadas por José Polo han hecho un mucho de justicia a la figura, a la labor y a la memoria de Fernández Ramírez, uno de nuestros venerables maestros; ahora hace falta que los que deseen seguir aprendiendo le hagan también justicia como lectores de sus obras. 